\title{
A new transgenic mouse line for tetracycline inducible transgene expression in mature melanocytes and the melanocyte stem cells using the Dopachrome tautomerase promoter
}

\author{
Susan L. Woods $\cdot$ J. Michael Bishop
}

Received: 5 April 2010/Accepted: 10 June 2010/Published online: 25 June 2010

(C) The Author(s) 2010. This article is published with open access at Springerlink.com

\begin{abstract}
We have generated a novel transgenic mouse to direct inducible and reversible transgene expression in the melanocytic compartment. The Dopachrome tautomerase $(D c t)$ control sequences we used are active early in the development of melanocytes and so this system was designed to enable the manipulation of transgene expression during development in utero and in the melanocyte stem cells as well as mature melanocytes. We observed inducible lacZ and GFP reporter transgene activity specifically in melanocytes and melanocyte stem cells in mouse skin. This mouse model will be a useful tool for the pigment cell community to investigate the contribution of candidate genes to normal melanocyte and/or melanoma development in vivo. Deregulated expression of the protooncogene $M Y C$ has been observed in melanoma, however whether MYC is involved in tumorigenesis in pigment cells has yet to be directly investigated in vivo. We have used our system to over-express $M Y C$ in the melanocytic compartment and show for the first time
\end{abstract}

S. L. Woods · J. M. Bishop

G.W. Hooper Research Foundation, University of California San Francisco, 513 Parnassus Ave, San Francisco, CA 94143-0552, USA

S. L. Woods $(\bowtie)$

Oncogenomics Lab, Division of Genetics \& Population Health, The Bancroft Centre, Queensland Institute of Medical Research, 300 Herston Rd, Herston, QLD 4006, Australia

e-mail: susan.woods@qimr.edu.au that increased $M Y C$ expression can indeed promote melanocytic tumor formation.

Keywords MYC $\cdot$ Transgenic $\cdot$ Dct $\cdot$ Melanoma · Tetracycline $\cdot$ Dopachrome tautomerase

\section{Introduction}

Despite the differences between mouse and man, the use of mouse models to study melanocyte biology and melanoma has significantly contributed to our understanding of this field (Walker and Hayward 2002). Melanocytes are pigment-producing cells derived from the neural crest. They are primarily found in the hair follicle in adult mouse skin, but are also located in the epidermis in non-hairy regions and the stria vascularis of the ear and around the eye. Specialized organelles within melanocytes termed 'melanosomes' contain enzymes that catalyse the multi-step synthesis of melanin including tyrosinase (Tyr), dopachrome tautomerase (Dct or Tyrp2) and tyrosinase-related protein 1 (Tyrp1). During development, the expression of transcripts encoding these enzymes is spatio-temporally regulated. Dct is the first gene to be expressed from embryonic day 9 (E9.0) in the presumptive retinal pigmented epithelium (RPE) of the eye, followed by expression from E9.5 in the telencephalon and at E10.5 in melanoblasts throughout the embryo after they leave the neural crest (Steel et al. 1992; Mackenzie et al. 1997; 
Wilkie et al. 2002; Hornyak et al. 2001). In comparison, Tyr and Tyrpl gene expression is slightly delayed in the RPE and melanoblasts during development, whilst expression of all three is maintained in melanocytes in the adult (Beermann et al. 1992; Steel et al. 1992; Beermann 1999; Murisier et al. 2006). In the adult hair follicle, Tyr protein expression is only detected in nonproliferating, differentiated melanocytes (Botchkareva et al. 2003) whilst Dct protein expression also marks the melanocyte stem cells (MSC).

The tetracycline regulatory (Tet) system has been widely used in different mouse models to enable temporal and site specific transgene expression, including models that target the melanocyte compartment (Giuriato et al. 2004; Gimenez et al. 2004; Yajima et al. 2006). An elegant example of this was the demonstration of the requirement for expression of an intiating oncogene for tumor maintenance, specifically HRASV12, in the melanocytic compartment (Chin et al. 1999). Unfortunately for melanoma researchers, this mouse also exhibits transgene expression in the prostate epithelium (Jeong et al. 2008).

Here we have used Dct promoter sequences to target Tet-responsive transgene expression to the mouse pigment cell compartment, including the MSC population. Unlike the other tyrosinase family members, Tyr and Tyrp1, Dct expression is consistently detected in melanoma samples, even amelanotic tumors (Orlow et al. 1995; Pak et al. 2001). Thus the transgenic mouse line described here will be a useful tool for the pigment cell community, enabling inducible transgene expression during melanocyte development, in MSCs and their progeny and to investigate the contribution of candidate genes to melanoma in vivo. Furthermore, we have used this system to over-express $M Y C$ in the melanocytic compartment and show that increased MYC expression can indeed promote melanocytic tumor formation.

\section{Results and discussion}

Mouse Dct promoter sequence directs inducible reporter gene expression specifically to melanoma cells in culture

To produce melanocyte specific expression of the reverse-tetracycline transactivator (rtTA) we generated the construct depicted in Fig. 1 a i. We chose the $\mathrm{rtTA} 2^{\mathrm{S}}-\mathrm{M} 2$ variant that has not commonly been used in transgenic mice (Gossen et al. 1995). We reasoned that this version would be superior to the original rtTA (as used in the earlier Tyr-rtTA model) because of its increased sensitivity to doxycycline (dox) and lower non-specific activation in the absence of dox (Berens and Hillen 2003; Chin et al. 1999). This construct was tested for cell-type specific expression and inducibility using a Tet-response element (TRE) containing Luciferase reporter (TRE2-LUC) and results were replicated using a second TREtight-EGFP reporter (data not shown). The TRE2-LUC reporter alone was not responsive to the addition of dox in any cells tested (Control, Fig. 1 a ii, iii, data not shown). Using a ubiquitously active promoter (CAAG) to control rtTA2 ${ }^{\mathrm{S}}$-M2 expression, we observed the very low background activity of the $\mathrm{rtTA}_{2}{ }^{\mathrm{S}}-\mathrm{M} 2$ protein in the absence of dox, which is similar to reporter alone levels, and the inducibility of the protein and reporter with the addition of dox (Fig. 1 a ii, iii). Transfection of the Dct/ rtTA2 ${ }^{\mathrm{S}}$-M2 expression construct and treatment of the cells with dox resulted in the specific induction of reporter gene activity in melanoma cells (D40 and B16F0), but not in other non-melanocytic cell lines (Fig. 1 a ii, iii, data not shown). Thus the $D c t /$ rtTA2$^{\mathrm{S}}-\mathrm{M} 2$ construct generates inducible transgene expression specifically in cells of the melanocytic lineage.

Generation and selection of $D c t / \mathrm{rtTA}^{\mathrm{S}}$-M2 transgenic mice

In order to develop a mouse model in which transgene expression can be manipulated in a tetracyclineinducible manner in mature melanocytes and the MSCs, we generated transgenic mice using the Dctl rtTA2 ${ }^{\mathrm{S}}$-M2 construct (Fig. 1a i). Founder lines were screened for the presence and maintenance of singlesite integration of the transgene by southern blot (Fig. 1 b, individual lines referred to as Det93 and Dct99). Expression of the $r t T A 2^{S}-M 2$ mRNA by realtime RT-PCR in samples from whole back and foot pad skin was detected in Dct93 mice but not control mice (data not shown).

The Dct promoter selectively drives transgene expression in the melanocytic compartment in $D c t$-rtTA mice

Dct promoter sequences have been used previously to produce multiple transgenic mouse lines (Zhao 
a
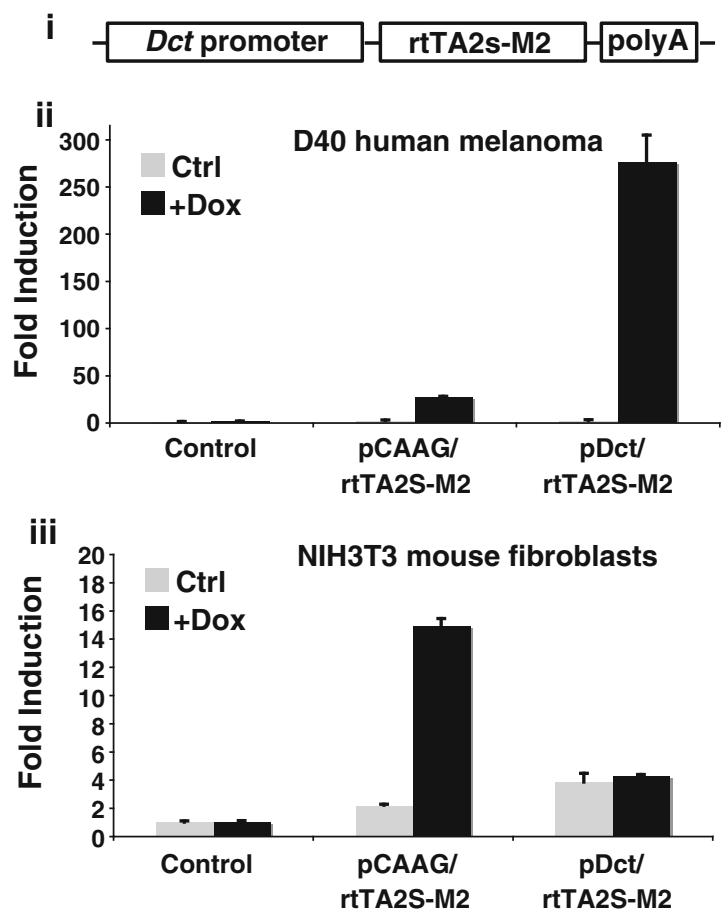

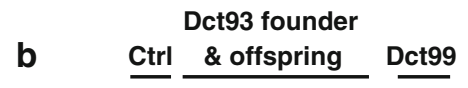
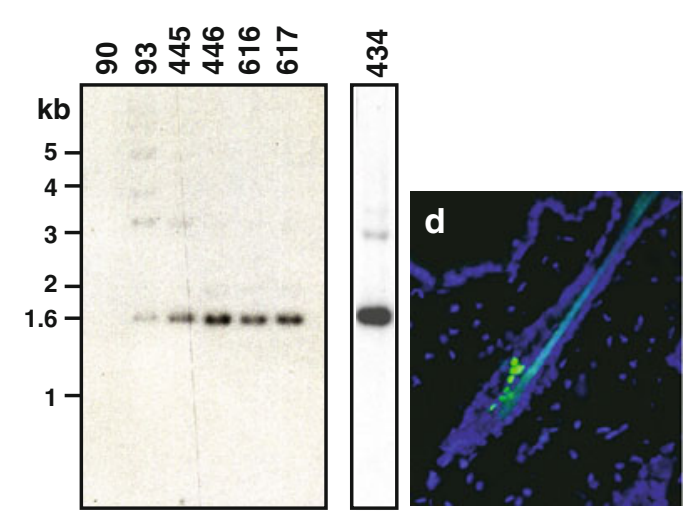

Fig. 1 Generation of a transgenic mouse line for inducible transgene expression in the pigment cell compartment. a. $i$, Schema of the Dct/rtTA2 ${ }^{\mathrm{S}}$-M2 construct, Dopachrome tautomerase (Dct) promoter, reverse tetracycline transactivator $\mathrm{rtTA} 2{ }^{\mathrm{S}}-\mathrm{M} 2$ variant cds and $\beta$-globin polyA tail. $i i-i i i$, Luciferase assays from cells transfected with a TRE2-LUC reporter and a GFP-expression plasmid (Control), or expression plasmid for $\mathrm{rtTA} 2^{\mathrm{S}}$-M2 under the control of a constitutively active promoter (pCAAG/rtTA2 $\left.{ }^{\mathrm{S}}-\mathrm{M} 2\right)$ or the $D c t$ promoter $\left(D c t / \mathrm{rtTA} 2^{\mathrm{S}}-\mathrm{M} 2\right)$. Relative luciferase activity was normalized to the reporter with control transfection in the absence of dox, transfections were performed in quadruplicate, error bars depict SD. b, southern blot showing transgenic mouse founder lines Det93 and Dct99
C
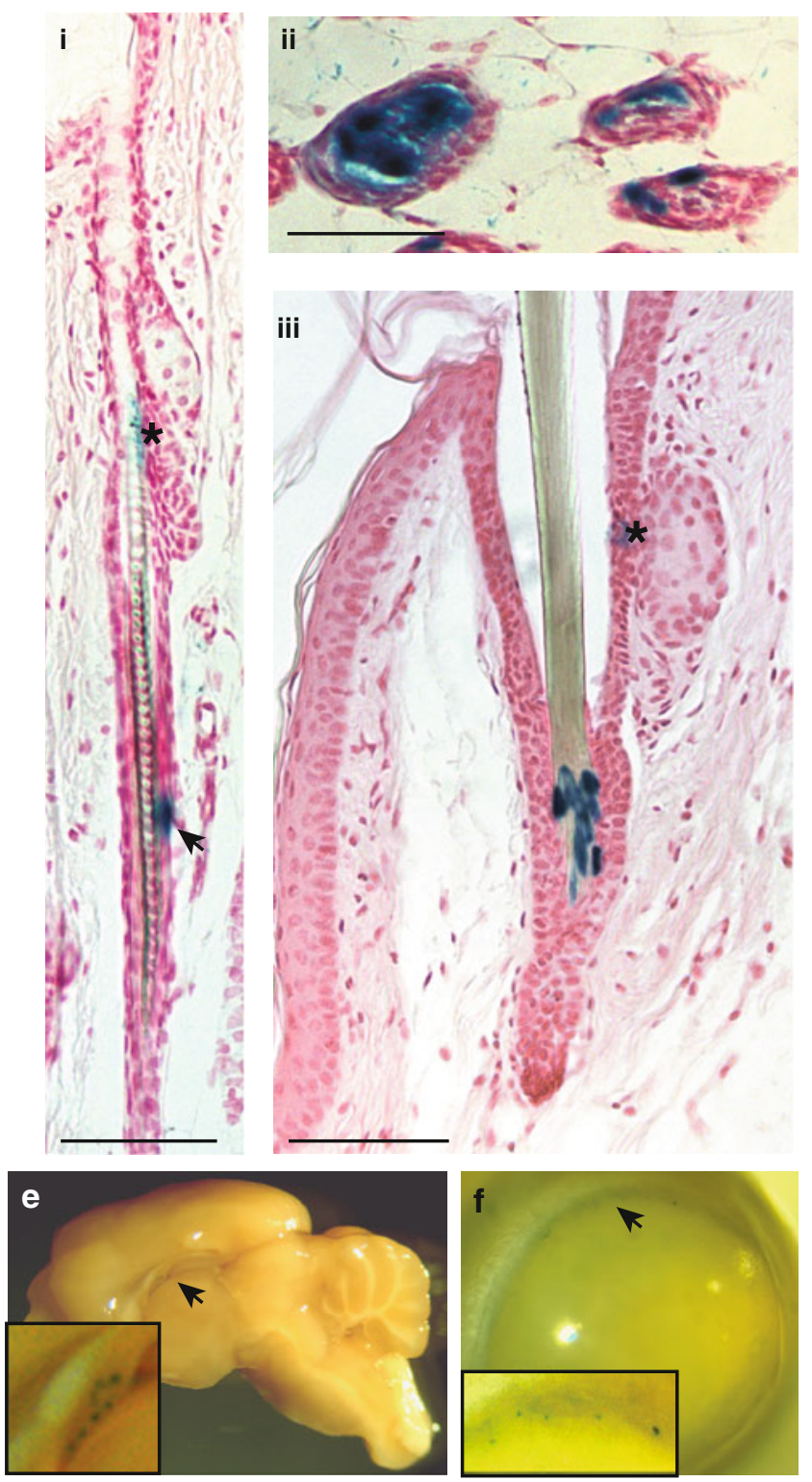

contain single genomic transgene integration sites, control (Ctrl) mouse does not contain transgene. c, In sections of the hair follicle in dorsal $(i, i i)$ and tail (iii) skin, melanoctye stem cells in the lower permanent portion of the hair follicle $(i)$ and mature melanocytes in the bulb region of the follicle (ii, iii) express lacZ in Dct93; TRE-lacZ mice on dox diet. * denotes endogenous lac $Z$ expression associated with the sebaceous gland, arrow indicates position of melanocyte stem cell. d, GFP positive melanocytes are visible in follicular melanocytes in dorsal skin of Dct93;TRE-H2bGFP mice on dox diet. e, Dct93; TRE-lacZ mice on dox exhibit lacZ expression in a small number of cells in the brain, the position is consistent with rostral migratory stream, and the eye (f). (Scale bars:100 $\mu \mathrm{m})$ 
and Overbeek 1999; Pollock et al. 2003; Mackenzie et al. 1997). The identical Dct promoter fragment that we use here was incorporated in the commonly used Dct-lacZ mouse (Mackenzie et al. 1997). The expression of lacZ has been extensively examined in the Dct-lacZ mouse and it faithfully recapitulates endogenous Dct expression in the developing embryo, with the exception of some unexpected lacZ expression in the caudal nerves at E10.5 (Mackenzie et al. 1997). We desired transgenic mice that express the rtTA2 $2^{\mathrm{S}}-\mathrm{M} 2$ protein in the melanocytic compartment and that are capable of inducing expression of TRE-regulated genes in those cells. To test whether this was the case for any of our mouse lines, we crossed our founder mice to TRE-lacZ and TRE-H2BGFP containing mouse reporter lines (Blanpain et al. 2004; Redfern et al. 1999). In double transgenic mice fed a dox diet a number of our lines exhibited lacZ expression in the melanocytes in the hair follicle by whole mount staining of adult back and tail skin, that was not observed in control mice (data not shown). We selected line Dct93 for high level lacZ expression in melanocytes in adult back and tail skin and in cells consistent positionally with the MSCs (Fig. 1 c). Likewise skin samples from Dct93; TRE-H2bGFP double transgenic mice fed a dox diet for 7 days contained GFP positive nuclei within the hair follicle that were not observed in samples from mice of the same genotype without dox diet (Fig. 1d, data not shown). The TREH2bGFP reporter mouse line is particularly useful for ready detection of melanocytic cells and tumors in which the driver is active.

Apart from expression in follicle melanocytes and MSC, Dct is also expressed in the mouse brain during development (Steel et al. 1992; Jiao et al. 2006). We extended our reporter analysis to include the adult brain and indeed in the Dct93; TRE-lac $Z$ double transgenics fed a dox diet we observed a very few lacZ positive cells in the brain (Fig. 1e). The position of these cells was consistent with the rostral migratory stream, similar to the observations of Jiao and colleagues using Dct-lacZ mice. lacZ expression was also present in the eye of Dct93; TRE-lacZ mice fed a dox diet. In whole mount the staining appeared in a limited number of cells approximately positioned above the ora serrata (Fig. 1f). We did not perform a more detailed analysis of expression in the brain or eye.
Mouse Dct93 line can be used to drive oncogene expression in the melanocytic compartment to promote melanoma formation

Deregulated expression of the proto-oncogene $M Y C$ has been reported in a wide range of human cancers, including melanoma (Ricaniadis et al. 2001; Ross et al. 2006; Greulich et al. 2000). While MYC overexpression has been observed in human and mouse models of melanoma, the effect of directed overexpression of MYC in the melanocytic compartment in vivo has not been reported. To determine whether $M Y C$ expression is sufficient for tumor formation in melanocytes in the mouse we crossed the Dct93 line to TRE-MYC mice (Felsher and Bishop 1999). Dct93 alone and Dct93;TRE-MYC mice were fed a diet containing dox to promote expression of the $M Y C$ transgene. Of note is the small amount of $M Y C$ expression detected by RT-PCR in whole back skin samples from mice with the TRE-MYC transgene alone, suggesting that this TRE-MYC transgene is partially 'leaky' in the skin (Fig. 2 a). This primer/ probe set is specific for the human MYC expressed from the transgene and does not recognize endogenous $M y c$ (data not shown). With the addition of dox to the diet of Dct93;TRE-MYC mice there was a 2.311 fold increase in the amount of $M Y C$ mRNA detected in whole back skin samples (Fig. 2a). Thus, similar to the reporters (Fig. $1 \mathrm{c}, \mathrm{d}$ ), the system is still inducible despite the background MYC transgene 'leak'. However due to this leak we only followed cohorts of Dct93 single transgenic animals and Det93; TRE-MYC mice all on dox diets and monitored skin tumor development for at least 18 months.

Melanocytic tumors formed with low penetrance (only 2 mice out of 26) when $M Y C$ was expressed in Dct93; TRE-MYC mice (on dox, $N=26$ ). This low incidence of tumor formation was not increased by neonatal UV irradiation, which has been shown to promote melanoma development in other mouse models (Noonan et al. 2001; Hacker et al. 2005; Broome Powell et al. 1999). The tumors were nodular, low grade or benign melanocytic tumors composed of cohesive sheets of melanocytic cells with epitheloid, ovoid and spindled morphologies with no obvious epidermal involvement. No melanocytic tumors were observed in Dct93 alone control mice without $M Y C$ expression (on dox, $N=24$ ). The 
a

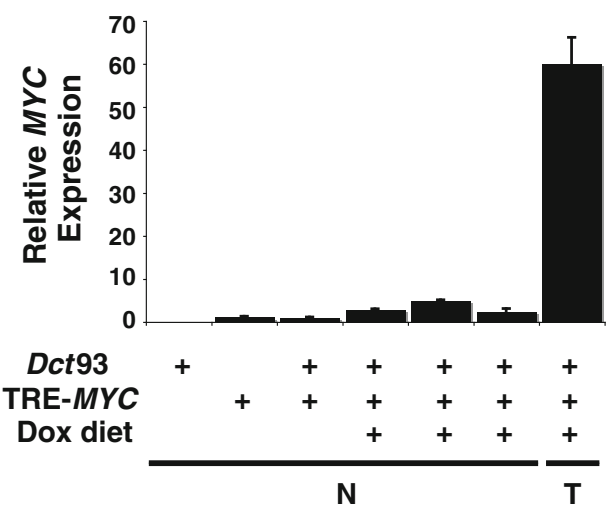

b

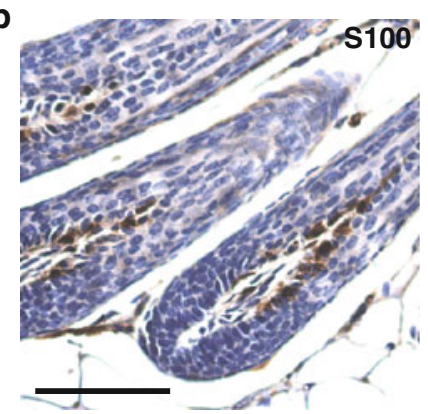

c

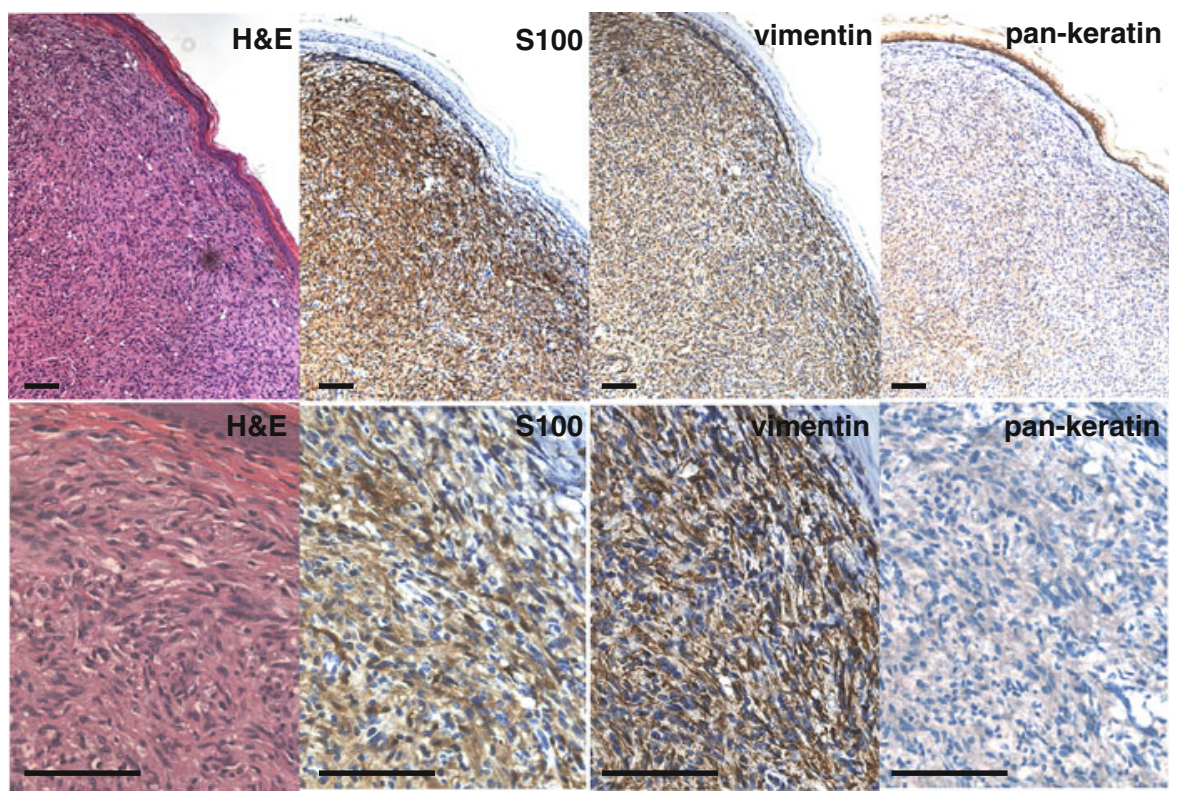

Fig. 2 The Dct93 transgenic mouse line can be used to direct oncogene expression to the melanocytic compartment to promote tumor formation, albeit with low penetrance for $M Y C$. a, Relative $M Y C$ expression normalized to $G A P D H$ levels by RT-PCR in normal back skin $(N)$ or tumor $(T)$ from mice of the indicated genotypes, each bar represents an individual mouse. Error bars depict SD. b, Specific positive staining (brown) of normal follicular melanocytes in dorsal

melanocytic origin of skin tumors was verified using a panel of lineage specific immunohistochemical markers including S100 and vimentin (Fig. 2 c). Tumors were negative for pan-keratin (Fig. 2 c). The specificity of S100 staining was observed in sections containing hair follicles with resident hair bulb melanocytes (Fig. 2 b). Melanocytic tumors were only found in the tail skin. Expression of $M Y C$ was increased approximately 20 -fold in the melanocytic mouse skin used as a control for S100 immunohistochemistry, counter stain is blue. c, Similar to human melanoma, tumors arising in tail of Dct93; TRE-MYC mice are positive (brown) for the melanoma antigens, S100 and vimentin and negative for the epithelial marker, pan-keratin. Bottom row depicts the same samples just at higher magnification than the top row. (Scale bars: $100 \mu \mathrm{m}$ )

tumor compared to normal whole skin from the same individual (Fig. 2a). Similar to a recently reported melanocytic mouse tumor model, we found no evidence from sequencing RT-PCR products containing the Braf or Nras coding sequences of nonsynonomous mutations in either cDNA in the melanocytic tumors analysed (Ohtani et al. 2008).

We report here the generation of a transgenic mouse line to enable inducible and reversible 
transgene expression in the melanocytic compartment. The Dct control sequences are active early in the development of melanocytes and so this system will enable the manipulation of transgene development in utero and in the adult, in the melanocytes and the MSCs. Using this model we have shown that $M Y C$ can act as an oncogene in melanoma development. However, we conclude that unlike other tissues (Felsher and Bishop 1999, Beer et al. 2004; Pelengaris et al. 1999; Pelengaris et al. 2002), increased expression of MYC may not be a potent tumor initiating event in mouse melanocytes in vivo.

\section{Methods}

Plasmid generation

rtTA2 ${ }^{\mathrm{S}}$-M2/rabbit $\beta$-globin polyA tail (EcoRI/PstI fragment from pCAGGS-rtTA-S2-M2, B. Welm) was subcloned into similarly digested $\mathrm{pBSKS}^{-}$. Subsequently the Sall mouse Dct promoter fragment from pPB2 [the $-3,181$ to +455 fragment as in (Mackenzie et al. 1997)] was inserted into similarly digested $\mathrm{pBSKS}^{-} /$ rtTA2 ${ }^{\mathrm{S}}-\mathrm{M} 2$, to produce $\mathrm{pBSKS}-D c t / \mathrm{rtTA} 2^{\mathrm{S}}-\mathrm{M} 2$. The sequence of the construct was verified, the transgene contains no introns.

\section{Luciferase reporter assays}

Human melanoma cell line D40 (Pavey et al. 2004) and mouse fibroblast NIH3T3 cells were routinely maintained in RPMI or DMEM, respectively, with $10 \% \mathrm{FBS}$ at $37^{\circ} \mathrm{C}$ with $5 \% \mathrm{CO}_{2}$. Sub-confluent cells in 24-well trays were transfected with $200 \mathrm{ng}$ pTRE2LUC-Puro reporter (Clontech), $50 \mathrm{ng}$ pRLTK internal control (Promega) and 250 ng expression plasmid per well (pCX-EGFP control, pCAGG/rtTA2 ${ }^{\mathrm{S}}$-M2 or pBSKS-Dct/rtTA2 ${ }^{\mathrm{S}}$-M2) with FugeneHD according to manufacturer's instructions (Roche). Doxycycline $(2 \mathrm{ug} / \mathrm{ml}$ final) was added to wells after $8 \mathrm{~h}$ as specified, cells were harvested $36 \mathrm{~h}$ after transfection and lysates were analysed for luciferase activity using the Dual Luciferase Reporter assay (Promega) according to the manufacturer's directions. D40 cells are readily transfectable with a transfection efficiency above $40 \%$, as estimated by the number of GFP positive cells in the control wells.
Generation and screening of transgenic mice

Transgenic mice were generated by the UCSF Transgenic core facility in the albino FVB/N strain using the $D c t / \mathrm{rtTA}^{\mathrm{S}}$-M2/polyA fragment. Mice were initially screened for the presence of the transgene by PCR using tail gDNA samples using forward primer 5'-CTGGGAGTTGAGCAGCCTAC-3' and reverse primer 5'-GTCTCAGAAGTGGGGGCATA-3'. Eight out of 26 animals were viable, fertile and positive for the transgene. They and their progeny were further analysed for single site transgene integration by Southern blot using a ${ }^{32} \mathrm{P}$-labelled EcoRI/NdeI fragment from $D c t / \mathrm{rtTA}_{2}{ }^{\mathrm{S}}$-M2. Whole back and tail skin was dissected from adult double transgenic Dct; TRE-lacZ or control TRE-lacZ alone mice on dox and the tissue stained for lac $Z$ expression as per the manufacturer's instructions (Chemicon). Samples were subjected to formaldehyde fixation and paraffin embedding, sectioned and analysed for lac $Z$ positive cells. lacZ positive cells were not observed in control mice. Fresh frozen OCT skin sections taken from control and Dct93; TRE-H2bGFP mice on dox diet for seven days were counter-stained with Hoechst and examined for GFP positive nuclei.

Mouse mating and UV irradiation for tumor studies

Animal experimentation was approved by the Committee for Animal Research at the University of California, San Francisco. TRE-MYC (Felsher and Bishop 1999) (line 36A) mice had been maintained as heterozygotes for the transgene and backcrossed to $\mathrm{FVB} / \mathrm{N}$ for at least 6 generations before crossing to the Dct93 line. Mice were placed on doxycycline (Dox diet pellets, Bio-Serv) containing chow either in utero at E15 or at weaning. Mice were UV irradiated on postnatal day 2-5 using 3 cascade-phosphor UV-B lamps (peak $313 \mathrm{~nm}$, Tyler Research). Exposure time was calculated to provide $4-7 \mathrm{~kJ} \mathrm{~m}^{2}$ in the single dose with UV dosimeter calibrated for UVB radiation, which produced noticeable erythema and mild oedema in some cases. Higher doses [as described in (Noonan et al. 2001)] were discontinued as particularly at postnatal day 2-3, such high doses caused excessive erythema \& oedema in this strain and mice had to be euthanized. Mice were monitored for tumor burden and euthanized as necessary (Dct93;TRE-MYC mice with 
tail tumors were euthanized between 10 and 17 months due to tumor burden) or followed for at least 18 months. Tumors and normal skin samples were harvested for FFPE and fresh frozen for RNA isolation.

\section{RNA isolation, RTPCR and sequencing}

Mouse normal skin and tumor samples were homogenized in TriReagentLS (Sigma) and total RNA prepared according to the manufacturers' instructions. cDNA synthesis was performed using SuperscriptII (Invitrogen) and cDNA samples analysed using real-time PCR for expression of $M Y C$ and GAPDH (Taqman, Applied Biosystems). The relative expression of $M Y C$ compared to GAPDH expression was determined using the $\Delta \Delta \mathrm{Ct}$ method (Applied Biosystems). RT-PCR products covering the entire coding sequence of Braf and Nras mRNAs were sequenced from normal and tumor samples.

\section{Immunohistochemistry}

FFPE Sects. $4 \mu \mathrm{m}$ thick were stained for S100 (1:50, Abcam), vimentin (1:200, Sigma) and pan-keratin (1:200, Sigma) according to the manufacturer's instructions (Vector Labs) with sodium citrate antigen retrieval.Slides were counterstained with Hematoxylin Gill\#3 (Fisher Scientific) to produce blue, nuclear counterstain.

Acknowledgments We thank members of the Bishop lab for insightful discussions, Luda Urisman for technical assistance, Prof. Nicholas K. Hayward for support of this project, Dr. Graeme Walker for critical reading of the manuscript, Peter Budd \& Prof. Ian Jackson (MRC Human Genetics Unit, Edinburgh, UK) for mouse Dct promoter clone and Prof. Wolfgang Hillen (Friedrich-Alexander University, Erlangen, Germany) for $r t T A 2^{S}-M 2$ clone.

Open Access This article is distributed under the terms of the Creative Commons Attribution Noncommercial License which permits any noncommercial use, distribution, and reproduction in any medium, provided the original author(s) and source are credited.

\section{References}

Beer S, Zetterberg A, Ihrie RA, Mctaggart RA, Yang Q, Bradon N, Arvanitis C, Attardi LD, Feng S, Ruebner B et al (2004) Developmental context determines latency of MYCinduced tumorigenesis. PLoS Biol 2:e332
Beermann F (1999) The tyrosinase related protein-1 (Tyrp1) promoter in transgenic experiments: targeted expression to the retinal pigment epithelium. Cell Mol Biol (Noisyle-grand) 45:961-968

Beermann F, Schmid E, Schutz G (1992) Expression of the mouse tyrosinase gene during embryonic development: recapitulation of the temporal regulation in transgenic mice. Proc Natl Acad Sci USA 89:2809-2813

Berens C, Hillen W (2003) Gene regulation by tetracyclines. Constraints of resistance regulation in bacteria shape TetR for application in eukaryotes. Eur J Biochem 270:31093121

Blanpain C, Lowry WE, Geoghegan A, Polak L, Fuchs E (2004) Self-renewal, multipotency, and the existence of two cell populations within an epithelial stem cell niche. Cell 118:635-648

Botchkareva NV, Botchkarev VA, Gilchrest BA (2003) Fate of melanocytes during development of the hair follicle pigmentary unit. J Investig Dermatol Symp Proc 8:76-79

Broome Powell M, Gause PR, Hyman P, Gregus J, LluriaPrevatt M, Nagle R, Bowden GT (1999) Induction of melanoma in TPras transgenic mice. Carcinogenesis 20:1747-1753

Chin L, Tam A, Pomerantz J, Wong M, Holash J, Bardeesy N, Shen Q, O'hagan R, Pantginis J, Zhou H et al (1999) Essential role for oncogenic Ras in tumour maintenance. Nature 400:468-472

Felsher DW, Bishop JM (1999) Reversible tumorigenesis by MYC in hematopoietic lineages. Mol Cell 4:199-207

Gimenez E, Lavado A, Giraldo P, Cozar P, Jeffery G, Montoliu L (2004) A transgenic mouse model with inducible Tyrosinase gene expression using the tetracycline (Tet-on) system allows regulated rescue of abnormal chiasmatic projections found in albinism. Pigment Cell Res 17:363-370

Giuriato S, Rabin K, Fan AC, Shachaf CM, Felsher DW (2004) Conditional animal models: a strategy to define when oncogenes will be effective targets to treat cancer. Semin Cancer Biol 14:3-11

Gossen M, Freundlieb S, Bender G, Muller G, Hillen W, Bujard H (1995) Transcriptional activation by tetracyclines in mammalian cells. Science 268:1766-1769

Greulich KM, Utikal J, Peter RU, Krahn G (2000) c-MYC and nodular malignant melanoma. A case report. Cancer 89:97-103

Hacker E, Irwin N, Muller HK, Powell MB, Kay G, Hayward N, Walker G (2005) Neonatal ultraviolet radiation exposure is critical for malignant melanoma induction in pigmented Tpras transgenic mice. J Invest Dermatol 125: 1074-1077

Hornyak TJ, Hayes DJ, Chiu LY, Ziff EB (2001) Transcription factors in melanocyte development: distinct roles for Pax3 and Mitf. Mech Dev 101:47-59

Jeong JH, Wang Z, Guimaraes AS, Ouyang X, Figueiredo JL, Ding Z, Jiang S, Guney I, Kang GH, Shin E et al (2008) BRAF activation initiates but does not maintain invasive prostate adenocarcinoma. PLoS One 3:e3949

Jiao Z, Zhang ZG, Hornyak TJ, Hozeska A, Zhang RL, Wang Y, Wang L, Roberts C, Strickland FM, Chopp M (2006) Dopachrome tautomerase (Dct) regulates neural progenitor cell proliferation. Dev Biol 296:396-408 
Mackenzie MA, Jordan SA, Budd PS, Jackson IJ (1997) Activation of the receptor tyrosine kinase Kit is required for the proliferation of melanoblast in the mouse embryo. Dev Biol 192:99-107

Murisier F, Guichard S, Beermann F (2006) A conserved transcriptional enhancer that specifies Tyrp1 expression to melanocytes. Dev Biol 298:644-655

Noonan FP, Recio JA, Takayama H, Duray P, Anver MR, Rush WL, De Fabo EC, Merlino G (2001) Neonatal sunburn and melanoma in mice. Nature 413:271-272

Ohtani Y, Harada T, Funasaka Y, Nakao K, Takahara C, Abdel-Daim M, Sakai N, Saito N, Nishigori C, Aiba A (2008) Metabotropic glutamate receptor subtype-1 is essential for in vivo growth of melanoma. Oncogene 27:7162-7170

Orlow SJ, Hearing VJ, Sakai C, Urabe K, Zhou BK, Silvers WK, Mintz B (1995) Changes in expression of putative antigens encoded by pigment genes in mouse melanomas at different stages of malignant progression. Proc Natl Acad Sci USA 92:10152-10156

Pak BJ, Chu W, Lu SJ, Kerbel RS, Ben-David Y (2001) Lineage-specific mechanism of drug and radiation resistance in melanoma mediated by tyrosinase-related protein 2. Cancer Metastasis Rev 20:27-32

Pavey S, Johansson P, Packer L, Taylor J, Stark M, Pollock PM, Walker GJ, Boyle GM, Harper U, Cozzi SJ et al (2004) Microarray expression profiling in melanoma reveals a BRAF mutation signature. Oncogene 23:4060-4067

Pelengaris S, Littlewood T, Khan M, Elia G, Evan G (1999) Reversible activation of c-Myc in skin: induction of a complex neoplastic phenotype by a single oncogenic lesion. Mol Cell 3:565-577

Pelengaris S, Khan M, Evan GI (2002) Suppression of Mycinduced apoptosis in beta cells exposes multiple oncogenic properties of Myc and triggers carcinogenic progression. Cell 109:321-334
Pollock PM, Cohen-Solal K, Sood R, Namkoong J, Martino JJ, Koganti A, Zhu H, Robbins C, Makalowska I, Shin SS et al (2003) Melanoma mouse model implicates metabotropic glutamate signaling in melanocytic neoplasia. Nat Genet 34:108-112

Redfern CH, Coward P, Degtyarev MY, Lee EK, Kwa AT, Hennighausen L, Bujard H, Fishman GI, Conklin BR (1999) Conditional expression and signaling of a specifically designed Gi-coupled receptor in transgenic mice. Nat Biotechnol 17:165-169

Ricaniadis N, Kataki A, Agnantis N, Androulakis G, Karakousis CP (2001) Long-term prognostic significance of HSP-70, c-myc and HLA-DR expression in patients with malignant melanoma. Eur J Surg Oncol 27:88-93

Ross DA, Laing JH, Sanders R, Wilson GD (2006) Long term follow-up of c-myc, p53 and proliferation measurements in malignant melanoma. Eur J Surg Oncol 32:80-84

Steel KP, Davidson DR, Jackson IJ (1992) TRP-2/DT, a new early melanoblast marker, shows that steel growth factor (c-kit ligand) is a survival factor. Development 115:11111119

Walker GJ, Hayward NK (2002) Pathways to melanoma development: lessons from the mouse. J Invest Dermatol 119:783-792

Wilkie AL, Jordan SA, Jackson IJ (2002) Neural crest progenitors of the melanocyte lineage: coat colour patterns revisited. Development 129:3349-3357

Yajima I, Belloir E, Bourgeois Y, Kumasaka M, Delmas V, Larue L (2006) Spatiotemporal gene control by the Cre-ERT2 system in melanocytes. Genesis 44:34-43

Zhao S, Overbeek PA (1999) Tyrosinase-related protein 2 promoter targets transgene expression to ocular and neural crest-derived tissues. Dev Biol 216:154-163 